\title{
Electric Smell: Towards Electrically Reproducing Artificial Smell
} Sensations

This paper was downloaded from TechRxiv (https://www.techrxiv.org).

LICENSE

CC BY 4.0

SUBMISSION DATE / POSTED DATE

24-02-2022 / 03-03-2022

CITATION

Cheok, Adrian David; Karunanayaka, Kasun (2022): Electric Smell: Towards Electrically Reproducing Artificial Smell Sensations. TechRxiv. Preprint. https://doi.org/10.36227/techrxiv.19228449.v1

DOI

10.36227/techrxiv.19228449.v1 


\title{
Electric Smell: Towards Electrically Reproducing Artificial Smell Sensations
}

\author{
Kasun Karunanayaka, Member, IEEE, Adrian David Cheok, Member, IEEE
}

\begin{abstract}
Artificially reproducing smell sensations, without using chemical odorants, would change the future multisensory internet expe riences. This paper discusses a computer-controlled smell reproduction technology proposed for stimulating human olfactory receptors, using weak electric pulses. The proof of concept device discusses this this paper, generates rectangular-shaped weak electrical pulses with different currents $(1-5 \mathrm{~mA})$, frequencies $(0-30 \mathrm{kHz})$, and duty cycles $(0-100 \%)$. This device was tested by stimulating the middle nasal concha regions of 31 healthy human participants. For the stimulation parameters $1 \mathrm{~mA}$ with $70 \mathrm{~Hz}, 8$ participants reported chemical and fragrant smell sensations while 6 reported fruity, and sweet smell sensations. For 1 mA with 10 Hz, 8 participants reported sweet smells, while 6 reported chemical smell sensations. Key contributions of this paper are as follows: a. development information of a electrical smell actuation device, b. characterization of the smell and non-smell sensations produced, c. study the effects of odor sniffing ability before and after the stimulation, d. investigate users' perception on the usefulness of this technology.
\end{abstract}

Index Terms - Virtual Olfactory Sensations, Electrical Stimulation, Electric Smell, Multisensory Internet, Virtual Experiences

\section{INTRODUCTION}

D IGITIZING smell sense has become essential in multisensory communication, augmented reality, and virtual reality research [1]. Existing technolgical advancements for reproducing smell sensations are entirely depend on chemicals [2], [3], [4], [5], [6], [7], [8], [9]. These chemical-based technologies have limitations such as being expensive for long term use, require routine maintenance, and difficulty of controlling the distribution pattern of odor molecules through the air. Nevertheless, direct electrical stimulation of receptors has helped in the study of both hearing and sight, which is expected to lead to sensory prostheses.

The work discussed in this paper is a part of a large, long term, research project of the authors on developing digital taste and smell actuation technologies. We first presented a digital taste actuation technology using electrical stimulation in 2011 [10]. A communication protocol to transfer taste over the Internet was proposed in 2012 [11]. Another digital taste technology using thermal stimulation was recently published in the IEEE TVCG journal [12]. The concept of producing smell sensations using electrical stimulation was proposed by the authors in 2016 [13]. Image article of electrically stimulating human nasal conchae was published in the Medical Clinical Image Library in 2018 [14]. Further, a non-peerreviewed book chapter [15] described an early prototype with some initial test results but did not provide the detailed research results as shown in this paper.

This paper is the next expansion of our research and first peer-reviewed paper with latest user evaluation results. Here we describe the testing of this technology on human subjects. We have recorded 22 olfactory epithelium induced sensations. Further, we investigated the odor sniffing ability before and after the electrical stimulation. Finally, we studied the users' perception towards this technology in future scenarios. Our next objective is to investigate and identify sets of stimulation

Kasun Karunanayaka is with University of Colombo School of Computing, Sri Lanka, and Imagineering Institute, Malaysia, E-mail: ktk@ucsc.cmb.ac.lk Adrian David Cheok is with Imagineering Institute, Malaysia and iUniversity, Tokyo, Japan, adrian @imagineeringinstitute.org parameters that can produce smell sensations. If this approach becomes successful, we will be able to digitally communicate and reproduce smells through the internet as we do with the audio and visual sensations. This would solve the limitations of chemical-based systems and open up a new avenues for many research areas such as Human Computer Interaction (HCI), Augmented Reality (AR), Virtual Reality (VR), gaming, Internet shopping, and medicine.

This paper is organized as follows: Section II will discuss the previous works in electrical stimulation of the olfactory epithelium. Section III will provides an overview of the device. User evaluation and results will be discussed in section IV, while Section V will discuss advantages, limitations, future work, and potential applications of this technology.

\section{RESEARCH BACKGROUND}

Human nose is a part of the chemosensory system, which helps to discriminate a vast variety of odors and flavors. The ability to smell in humans is said to be weaker than other mammalians due to fewer smell genes in their body (for example, rodents have more than 1100 smell genes [16], while humans only have 350 functional genes [17]). On the other hand, humans have complex olfactory bulbs and orbitofrontal cortices, which provide them with more sensitive and dynamic abilities for the sense of smell [18], and as a result, [19] suggested that humans can detect at least 1 trillion different odors. However this claim was rebutted by [20], and proved that there were failures in the mathematical model used by [19]. Therefore, much concerning the sense of smell appears enigmatic and contradictory. This could be partially due to the inherent complexities in presenting odour stimuli and partially because all the relevant mechanisms involved are not yet identified.

The human olfactory system plays a key role in enhancing one's everyday life experiences via emotions and memory. Moreover, a memory of smell lasts longer and it is easy to recall than a memory acquired verbally [21]. Smell memories are thought to have proven qualities, such as resistance to interference, uniqueness, and independence from other modalities 


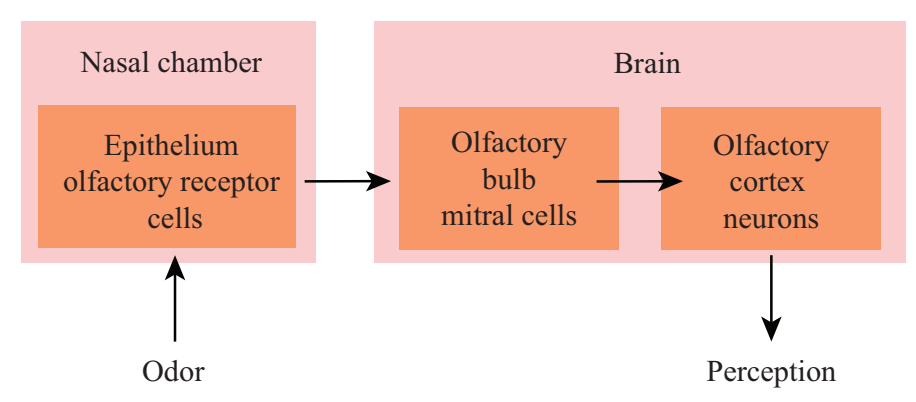

Fig. 1. Scheme of the human olfactory system.

known as "Proustian characteristics" [22]. Interestingly, smell, as well as taste, has been found to be directly connected with mood, stress, retention, and memory functions [23].

When the odor molecules enter the olfactory epithelium, they bind with olfactory receptors, which are expressed in olfactory sensory neurons in the nose [24]. Then, olfactory receptors trigger a series of signals within the cells that ultimately results in the opening and closing of ion channels. This increases the concentration of positive ions inside the olfactory cells. This depolarization causes the olfactory cells to release packets of chemical signals called neurotransmitters, which initiate a nerve impulse. Odor information is then relayed to many regions throughout the brain [25], which is then perceived as smell. This natural mechanism is shown in Fig 1 .

In HCI, VR, and AR the sense of smell is used to deliver multisensory experiences and sometimes to alter other sensory inputs [26], [27], [9], [5], [28]. Multisensory technologies and their applications interms of interaction, design, and challenges have been discussed recently in many places [29], [30], [31], [32], [33]. To avoid the pitfalls of the chemical based smell delivery systems, finding alternative methods that can effectively reproduce olfactory sensations without chemicals is becoming a necessity.

Electrical stimulation can create depolarization in the nerve cells, which can then induce action potentials with sufficient depolarization magnitude [34]. It can be argued that electrical stimulation of the olfactory receptors may reproduce smell sensations, as electric stimulation produce taste sensations in a practice known as electrogustometry [35]. Therefore, the research described in this paper is based on experimenting with sensations produced by electrical stimulation in the nasal cavity. Our approach of stimulation of the nasal cavity is shown in Fig 2

There are few experiments carried out on electrical stimulation of olfactory mucosa. In 1973 a study conducted in the medical field [36] stimulated the human olfactory neuroepithelium using anodal and cathodal stimulation. Odor perceptions, such as vanilla, almond, and bitter almond were reported for anodic stimulation while cathodic stimulation reported burnt sensation. However, attempts by [37] and [38] were failed to replicate similar results.

Authors of [38] recorded olfactory bulbar potentials using 2 $\mathrm{mA}$ and $0.5 \mathrm{~Hz}$; nevertheless, no smell sensation was reported by the subject. The same research team later developed an

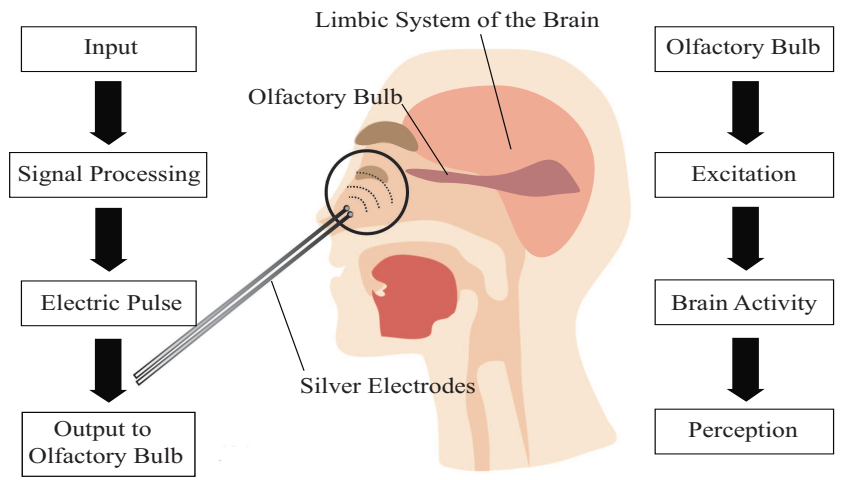

Fig. 2. The concept of stimulating human nasal concha using weak electric pulses.

alternative to psychophysical olfactometry using evoked olfactory bulbar potentials in electrical stimulation. However there were no sensation of smell reported during these experiments as well [39]. In another study [40], authors also failed to electrically generate smell perception notwithstanding simultaneous electrical stimulation-related evoked potentials recorded directly from the olfactory tract.

The latest report by [41] stimulated the olfactory neurons with electrical currents ranging from $0.05 \mathrm{~mA}$ to $0.8 \mathrm{~mA}$ with frequencies of $2 \mathrm{~Hz}, 10 \mathrm{~Hz}, 70 \mathrm{~Hz}, 90 \mathrm{~Hz}, 130 \mathrm{~Hz}$ and $180 \mathrm{~Hz}$. Odor perceptions were not reported during the experiment, however, they were able to measure several nonolfactory sensations such as pinpricks, flashes of light, cooling, tingling, and electrical current. Further, significant difference in perceived intensity of smell during the electrical stimulation was reported.

In an experiment with epilepsy patients, Kumar et. al [42] reported that 11 out of 16 subjects perceived smell sensations. Two subjects experienced pleasant smells while the rest experienced unpleasant smells. The stimulation was done using $3 \mathrm{~mA}, 6 \mathrm{~mA}$, and $9 \mathrm{~mA}$ currents with $50 \mathrm{~Hz}$ frequency for 5 seconds. The experiment took place on the ventral surface of the frontal lobe where subdural electrodes need to be implanted. Since this method is highly invasive it cannot be practically developed as a technology to reproduce smell sensations digitally.

The works mentioned above have delivered mixed results. Most importantly, electrical stimulation produced action potentials in the nerves during most of the experiments and in couple of cases smell sensations reported. In this study, we tested different range of stimulation parameters that other researchers did not use, such as current from $1 \mathrm{~mA}$ to $5 \mathrm{~mA}$ with frequencies $2 \mathrm{~Hz}, 10 \mathrm{~Hz}, 70 \mathrm{~Hz}$, and $180 \mathrm{~Hz}$. Furthermore, most of the previous works only discussed or measured limited number of sensations. We recorded results for 22 different sensations that electrical stimulation may produce that includes 10 smellrelated and 12 non-smell-related sensations. We believe this is useful to measure because the sense of smell is connected with other systems in the brain such as gustatory system, and limbic system which deals with emotions, memories, and arousal. Thus, it is evident that electrical stimulation can produce complex sensations. Secondly, this kind of characterization has 


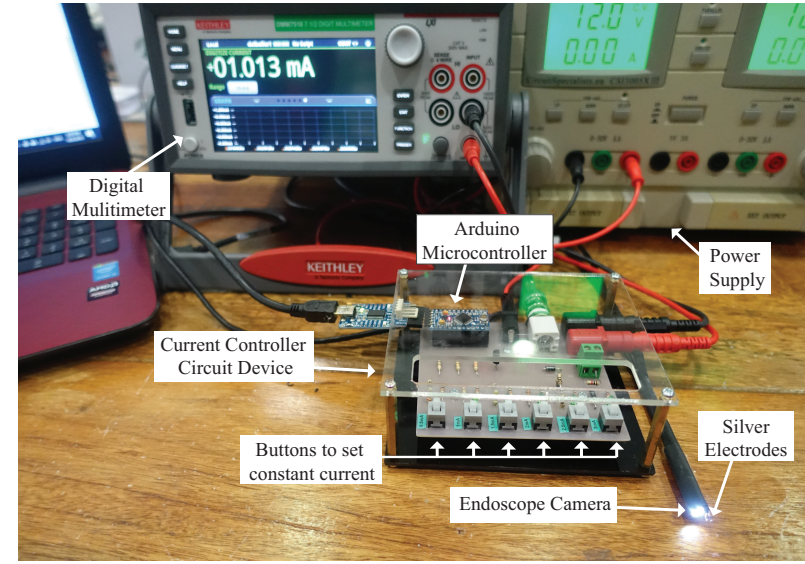

Fig. 3. Electric smell prototype: This device produces constant current output ranging from 1-5 mA with variable frequencies. The pair of silver electrodes attached to endoscope camera was used to stimulate nasal cavity with weak electrical pulses.

not been studied before, therefore, these results will be useful for future researchers in selecting ideal stimulation parameters.

Our approach is different from the works mentioned above from the medical field in many ways. Our main objective is to develop a controllable and repeatable digital technology to generate smell sensations without chemical odorants. We decided that this technology should be a device that can be plugged into computers and it should be able to be programmed and controlled through the computer. Also, this device needs to generate electric pulses of different frequencies, currents, pulse widths, and stimulation times. To provide more stimulation possibilities, we wanted this device to be capable of stimulating diverse sites at the ventral surface of the inferior, middle, and superior nasal concha. If electrical stimulation produces any kind of smell sensation using this proposed technology, we can represent that type of smell sensation as an electric signal, and then reproduce the same sensations on humans using electrical stimulation.

\section{DEVICE DESCRIPTION}

Fig 3 shows the computer-controlled digital device we used to stimulate olfactory receptors. It consists of a current controller circuit, an Arduino microcontroller, two silver electrodes attached with an endoscopic camera, a DC power supply, and a software program. The silver electrodes are custom made with dimensions of $100 \mathrm{~mm}$ in length and 0.5 $\mathrm{mm}$ in width. It also contains a spherical tip of $0.8 \mathrm{~mm}$ diameter at one end. This sphere tip makes contact with inner wall of the nose during the stimulation.

The controller circuit mainly functioned as a current controller. It can generate constant current square wave pulses from $0.5 \mathrm{~mA}$ up to $10.5 \mathrm{~mA}$ with a $1 \mathrm{~mA}$ difference. The amount of current generated by the circuit can be configured using five push buttons shown in Fig 3 . These buttons are configured to output $0.5 \mathrm{~mA}, 1 \mathrm{~mA}, 1.5 \mathrm{~mA}, 2 \mathrm{~mA}, 2.5 \mathrm{~mA}$, $3 \mathrm{~mA}$. By switching on one or more of them, it is possible to configure the output current from $0.5 \mathrm{~mA}$ to $10.5 \mathrm{~mA}$. (e.g., By activating both the $0.5 \mathrm{~mA}$ and $3 \mathrm{~mA}$ buttons together,

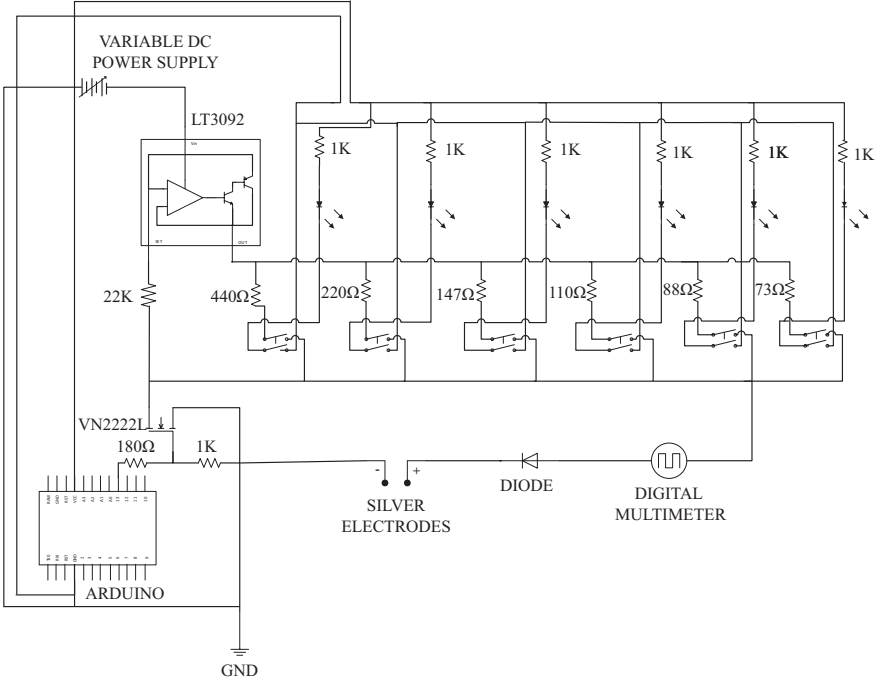

Fig. 4. Schematic of the current controller circuit.

TABLE I

MEASURED ACTUAL CURRENT OUTPUT AND ERROR

\begin{tabular}{ccc}
\hline Intended Value(mA) & $\begin{array}{c}\text { Observed Value } \\
(\mathbf{m A})\end{array}$ & Error \\
\hline 0.5 & 0.49 & $2 \%$ \\
1 & 1.02 & $2 \%$ \\
1.5 & 1.49 & $0.7 \%$ \\
2 & 1.98 & $1 \%$ \\
2.5 & 2.49 & $0.4 \%$ \\
3 & 3.02 & $0.7 \%$ \\
\hline
\end{tabular}

a total of $3.5 \mathrm{~mA}$ current will be produced). However, we found that $5 \mathrm{~mA}$ is the maximum harmless current for human subjects [43]. Therefore, we stimulated the subjects for a range between $1 \mathrm{~mA}$ to $4 \mathrm{~mA}$. This was similar to the range of stimulation currents which were used in [39] but we used different frequencies and stimulation times. The maximum load resistance of this device is up to $4 \mathrm{k} \Omega$. The power supply produces a variable voltage up to $30 \mathrm{~V}$.

Microcontroller program controls the frequency of stimulation pulses and stimulation time. For the user experiments, we programmed the device for four frequencies: $2 \mathrm{~Hz}, 10 \mathrm{~Hz}$, $70 \mathrm{~Hz}$, and $180 \mathrm{~Hz}$ which are identical to the stimulation frequencies used in 41$]^{1}$. However, we have tested these frequencies using much higher current $(1 \mathrm{~mA}-4 \mathrm{~mA})$ and these combination of current and frequency was never tested before on human subjects. We have recorded and analyzed the accuracy of the signal produced under different stimulation settings. Some sample measurements are showed in Fig 5 Regarding the amplitude, maximum of $2 \%$ error was recorded with compared to the intended current output and actual

\footnotetext{
${ }^{1}$ Authors of the particular paper said "The stimulation parameters we tested using this design were a continuous sine wave delivered at 5 frequencies: 2 , $10,70,90,130$, and $180 \mathrm{~Hz}$, and a burst mode (5 cycles, 100-s pulse width) delivered at 90 or $180 \mathrm{~Hz}$, all applied at currents ranging from 50 up to 800 A, at typically 10 A intervals. A typical experiment lasted about $1 \mathrm{~h} . "$
} 

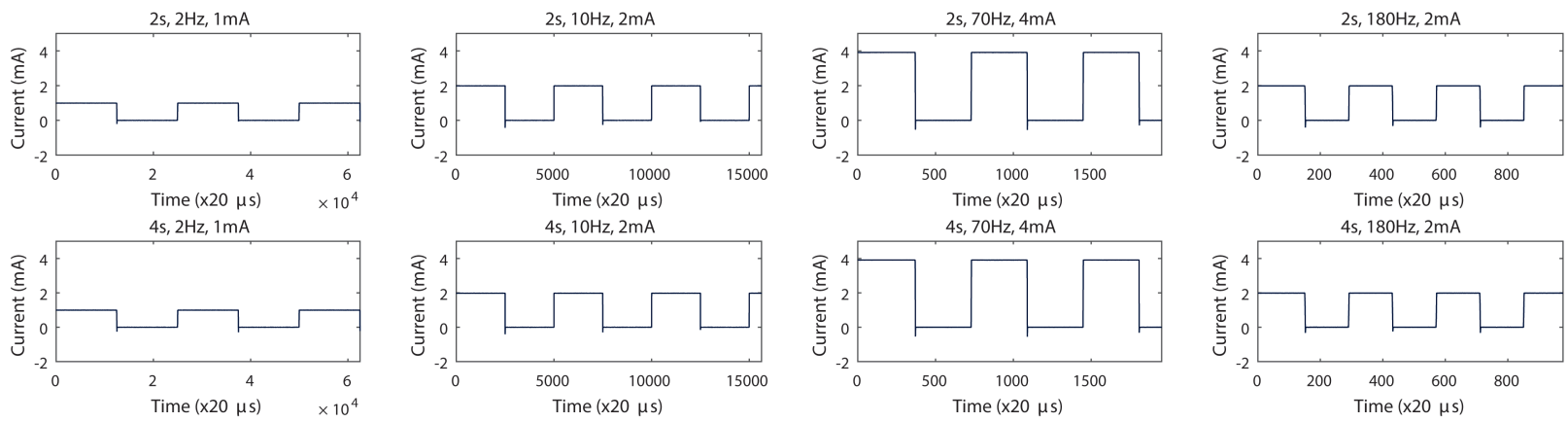

$4 \mathrm{~s}, 10 \mathrm{~Hz}, 2 \mathrm{~mA}$
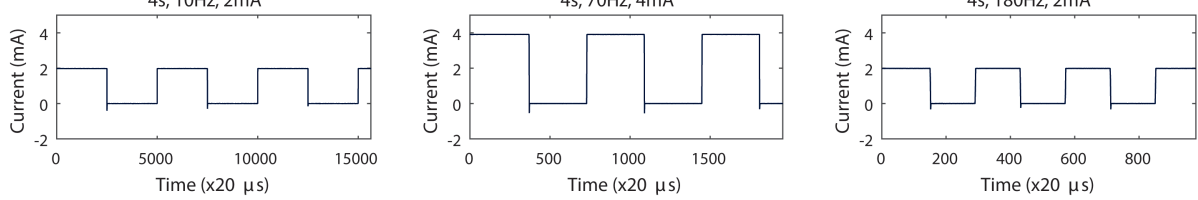

$8 \mathrm{~s}, 10 \mathrm{~Hz}, 2 \mathrm{~mA}$
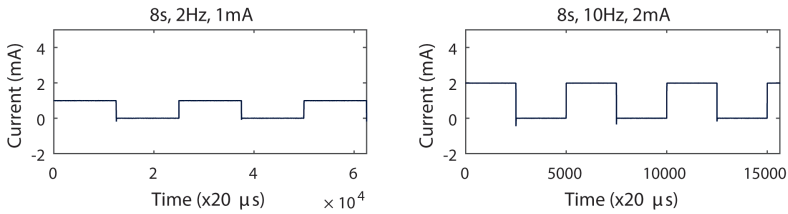

$8 \mathrm{~s}, 70 \mathrm{~Hz}, 4 \mathrm{~mA}$

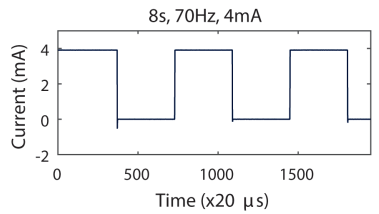

$8 \mathrm{~s}, 180 \mathrm{~Hz}, 2 \mathrm{~mA}$

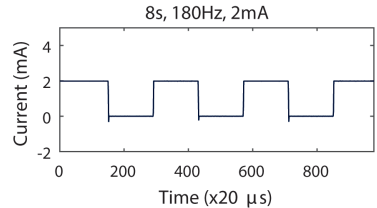

$0 \mathrm{~s}, 2 \mathrm{~Hz}, 1 \mathrm{~mA}$
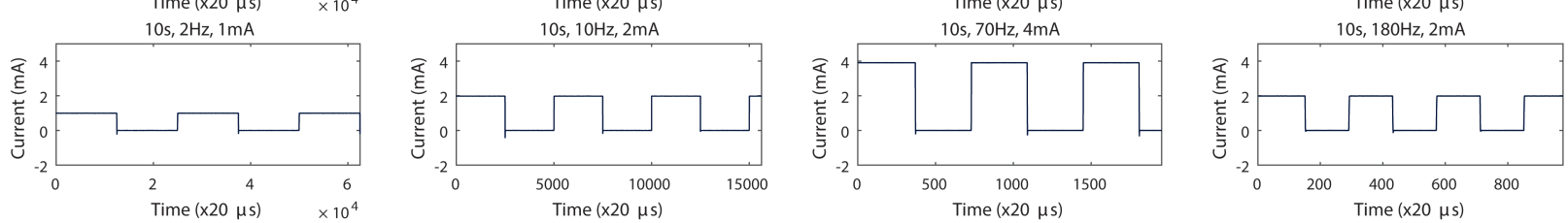

Fig. 5. Different stimulation patterns recorded from the device which used to stimulate human subjects. Maximum of $2 \%$ error and negative spikes at the falling edge was observed probably due to component tolerance and stray inductance

current output as reported in Table $[$. This is probably due to component tolerances. Negative spikes at the falling edge was recorded probably due to stray inductances. From the equation $V=L \frac{d i}{d t}$, a negative voltage was likely induced from stray currents, as there are considerable changes in current values during the transient phases.

For successful stimulation, electrodes need to read resistance from the skin. Therefore a digital multimeter was connected to the controller circuit to monitor the output current during the stimulation. Using the endoscopic camera, researcher who operate the device was able to see whether the two electrodes are near the area of stimulation and readings from the multimeter provided the confirmation of whether the two electrods are touching the surface of the skin. If the electrodes were not touching properly, the multimeter outputs $0 \mathrm{~mA}$. This device can be controlled using any serial port client and the based on the keyboard inputs received through a USB connection Arduino microcontroller produces the intended output signal.

\section{USER EVALUATIONS}

To investigate the effects of the device we tested it with human subjects in two ways: a. stimulate the nasal mucosa of subjects and record induced sensations, and b. study whether electrical stimulation modify the odor sniffing ability. 31 subjects (11 females, mean age $24.5 \pm 5.01$ ) participated in these experiments. Most of the participants were undergraduate students, age between 20 to 23 years old, and a few non student adults. The subjects were all below the age of 50 years. This selection was made because studies have revealed that ageing most often leads to decline of olfaction [44]. Each subject first filled out a questionnaire relating to his/her health status and allergies. Participants were physically screened

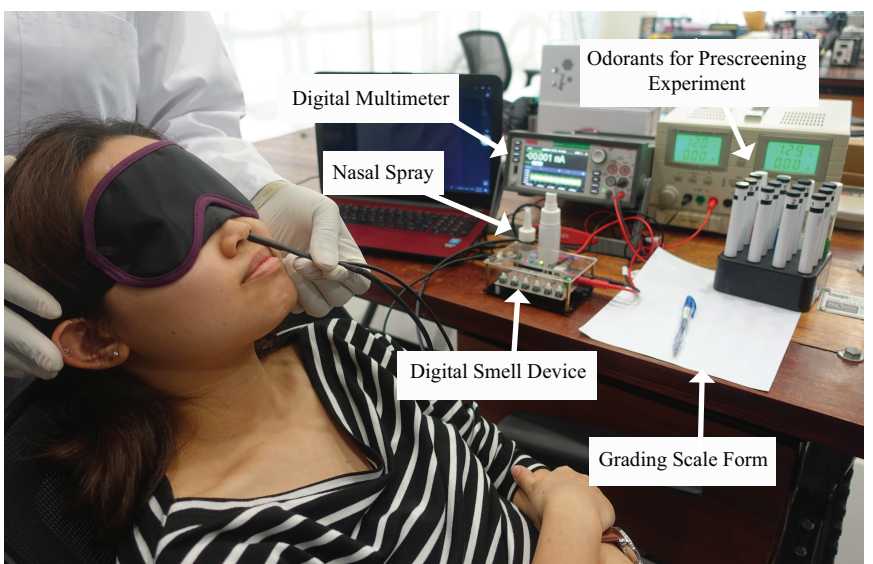

Fig. 6. Stimulating the nasal cavity of a participant using the electric smell device.

by answering some general well-being questions. They also confirmed whether they have intact olfaction, nasal congestion, non-use of chronic medication of any kind, no current head injury, and no history of mental ailment. Nevertheless, to assure participant had a clear and unharmed nasal passage, every experiment preceded by nasal endoscopic examination.

The study design was submitted to the institutional review board (IRB). Approval was gotten after some modifications bordering on safety of participants were made. Before beginning the experiment, the procedure was explained in details and participants filled and signed a consent form before participating in the experiment which was conducted according to the ethics guidelines approved by the IRB. Nevertheless, a participant was free to quit the experiment if he/she felt the procedure was uncomfortable. 


\section{A. Pre-screening Experiment: Sniffing of Known Odorants}

Here we aimed at determining the smelling competence of the participants and to study the effect of electrical stimulation on the nasal cavity by sniffing known odorants. In this regard, 5 known odorants (orange, cinnamon, banana, pineapple, and peppermint) were randomly presented to the participants. In order to conceal the colour of the odorants, they were presented in a non-translucent container and numbered 1 to 5. Participants by closing either the left or right nose, sniffed each odorant one at a time, identify the type of odorant, and rate its intensity using a grading scale. Water was used to reset the olfactory receptors to their original state, therefore, after each trial, participants were asked to sniff water before sniffing another odorant. The process was repeated for all 5 odorants. This was done to determine the competence of the subject to identify different smells, and to rule out anosmia prior to the main experiment. The participants repeated this procedure after the main electric stimulation to compare the intensity of the odorants.

\section{B. Electrical Stimulation of the Nasal Mucosa}

In this study our aim was to electrically stimulate the nasal mucosa to induce smell or other sensations. Hence, we targeted different areas at the uppermost layer of the inferior, middle and superior conchae, as well as the dorsal septum. Nevertheless, our stimulations were majorly at the middle turbinate where olfactory local field potentials are easily acquired [45]. Eight different current and frequency combinations $(1 \mathrm{~mA} / 2 \mathrm{~Hz}$, $1 \mathrm{~mA} / 10 \mathrm{~Hz}, 1 \mathrm{~mA} / 70 \mathrm{~Hz}, 1 \mathrm{~mA} / 180 \mathrm{~Hz}, 2 \mathrm{~mA} / 10 \mathrm{~Hz}, 2 \mathrm{~mA} / 70 \mathrm{~Hz}$, $2 \mathrm{~mA} / 180 \mathrm{~Hz}$, and $4 \mathrm{~mA} / 70 \mathrm{~Hz}$ ) were used as the stimulation parameters in this experiment. Order of using the stimulation parameters was randomized across the participants.

In a closed and comfortable room, participants were made to seat on an adjustable chair. We applied Azelatine ${ }^{2}$ nasal spray in both sides of the nose to abate sneezing. To reduce distractions, the participant's eyes was covered with an eye mask. With endoscope camera guidance, the stimulating silver electrodes was gently inserted into the nasal cavity and gradually brought into contact with the targeted areas, as shown in Fig 6. This was followed by electrical stimulations done concurrently with nasal breathing as though normal sniffing [46], 47].

We measured the induced sensations using a measurement index that can record intensities of 22 different sensations. The sensations were divided into two categories: The first category consisted of the 10 basic smells (fragrant, fruity, citrus, chemical, sweet, minty, Toasted/nutty, decay, and pungent) as characterize by [48]. The second category consisted of induced non-olfactory sensations, which include cooling, heating, electric, pinprick, tingling, numbness, metallic, burning, pleasant, pain, lingering, and pressure.

Each participant went through eight trials. Duration of electrical stimulation was fixed at $10 \mathrm{~s}$, with an inter-stimulus interval of $60 \mathrm{~s}$. Although, all stimulation parameters commenced with an initial current of $1 \mathrm{~mA}$ but was gradually

${ }^{2}$ Azelastine Nasal Spray, https://www.drugs.com/cdi/azelastine-spray.html and repeatedly increased until $5 \mathrm{~mA}$. During the interval between trials, participants filled a response form where they indicated the type of sensation perceived during and after every trial. Using a grading scale ranging from 0 (none) to 10 (strongest), they graded the intensity of the smell, before and after electric stimulation. The participants completed the response form for the eight trials, after which an analysis for each of the participants responses were made, and the parameters compared. The experiment lasted for about 45 minutes for each participant.

\section{1) Findings}

Out of the eight stimulation parameters used, $1 \mathrm{~mA}$ and 10 $\mathrm{Hz}$, and $1 \mathrm{~mA}$ and $70 \mathrm{~Hz}$ gave the most important results for smell related responses. Fig 7 shows the resulted sensations based on [48] categorization, reported by the participants in percentages. Chemical and fragrant smells was reported in $27 \%$ of the participants. Other smell sensations reported with $1 \mathrm{~mA}$ and $70 \mathrm{~Hz}$ includes fruity $20 \%$, sweet $20 \%$, toasted and nutty $17 \%$, minty $10 \%$, and woody $13 \%$. Other stimulation parameters, $1 \mathrm{~mA}$ and $10 \mathrm{~Hz}, 17 \%$ reported fragrant smell, $27 \%$ sweet, $10 \%$ chemical, and $10 \%$ woody. During the $4 \mathrm{~mA}$ and $70 \mathrm{~Hz}$ stimulation $82 \%$ reported pain (the mean intensity value received for pain was $2.95 \pm 0.85$ ), while $64 \%$ reported pressure.

Fig 7 also represents the mean intensities reported for each type of smell at different stimulation parameters. Intensity values were based on the 10 -point grading scale $(0=$ none and $10=$ strongest $)$.

Generally, intensity values were reported between 1 and 3. Participants reported they felt intense pain and tingling sensations for the combinations, $1 \mathrm{~mA} 180 \mathrm{~Hz}$ and $4 \mathrm{~mA}$ and $70 \mathrm{~Hz}$. Hence, we think combinations of high frequencies and high currents could be associated with pain sensation. We also observed at the same time that most participant reported pain when the stimulating electrodes were outside the olfactory cleft and touching the respiratory mucosa. Visual flashes were reported by two participants at stimulation of $4 \mathrm{~mA}$ and $70 \mathrm{~Hz}$. Similarly, a previous study [41] also reported visual flashes using $0.45 \mathrm{~mA}$ and $10 \mathrm{~Hz}$. Hence, we still do not understand the underlying factors contributing to most of the non-olfactory sensations.

\section{The Response Produced After Sniffing of Known Odor-} ants

To study the effect of electrical stimulation on the nasal mucosa, we compared the intensities of several odorants before and after stimulation. We tested the ability of each participant to identify different kinds of odorants. The five known odorants presented to the participants were, banana, cinnamon, orange, peppermint, and pineapple. Table II shows the result of odorant intensity before and after electrical stimulation of the nasal concha. As shown in the table, the intensity before and after stimulation was almost similar for all odorants, nevertheless, most participants verbally reported they felt the odorants smelled different after the electrical stimulation. In this study, shapiro-wilk test was employed to assess the distribution of data because the sample of respondents was less than 100 . The 


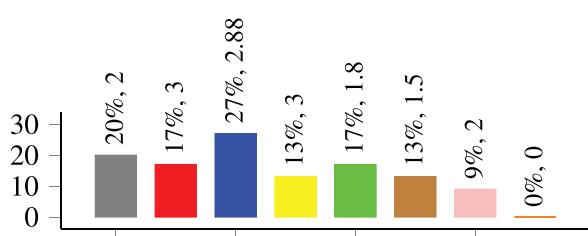

Fragrant
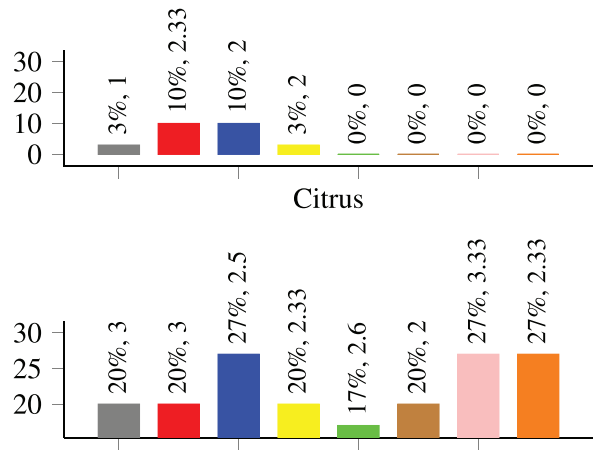

Chemical
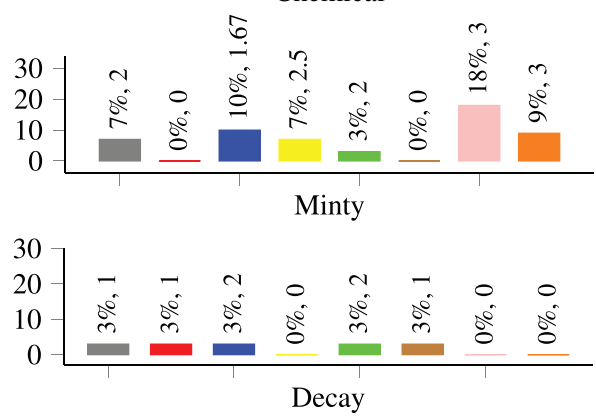

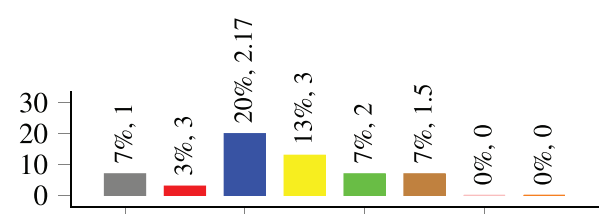

Fruity
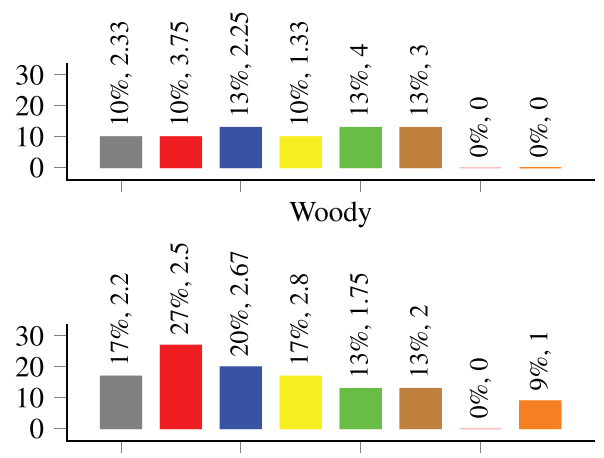

Sweet
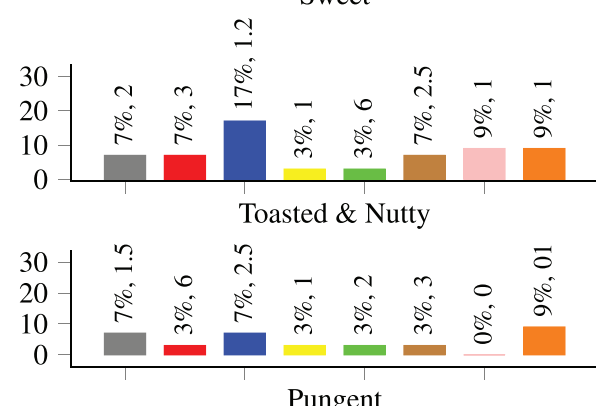

Pungent

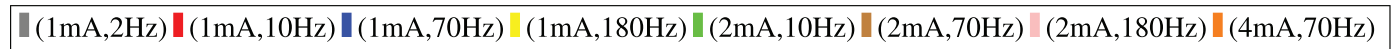

Fig. 7. Percentage of 10 basic smells generated during different electrical stimulations and mean perceived intensity of the particular smell (range: 0-no smell, 10-highest imaginable intensity).

TABLE II

MEAN INTENSITIES FOR SNIFNG KNOWN ODORANTS BEFORE AND AFTER ELECTRICAL STIMULATION'

\begin{tabular}{lll}
\hline Odorants & Mean before & Mean after \\
\hline Banana & 6.8 & 6.3 \\
Cinnamon & 5.7 & 5.2 \\
Orange & 6.1 & 5.8 \\
Peppermint & 6.9 & 6.5 \\
Pineapple & 5.8 & 5.8 \\
\hline
\end{tabular}

results show that data in this study were normally distributed. Hence, a paired sample t-test was conducted to compare the intensity of the odorants perceived by the participants before and after applying electrical stimulation conditions. There was a significant difference in the scores for cinnamon before electrical stimulations $(\mathrm{M}=5.73, \mathrm{SD}=1.946)$ and cinnamon after electrical stimulations $(\mathrm{M}=5.17, \mathrm{SD}=1.895)$ conditions; $\mathrm{t}(30)=2.288, \mathrm{p}=0.016$. However, there was no significant difference found in orange before $(\mathrm{M}=6.13, \mathrm{SD}=1.727)$ and after $(\mathrm{M}=5.77, \mathrm{SD}=2.061) ; \mathrm{t}(30)=1.514, \mathrm{p}=0.141$, banana before $(M=6.77, S D=1.892)$ and after $(M=6.29, S D$ $=2.179) ; \mathrm{t}(30)=1.360, \mathrm{p}=0.184$, pineapple before $(\mathrm{M}=5.84$, $\mathrm{SD}=1.934)$ and after $(\mathrm{M}=5.81, \mathrm{SD}=2.151) ; \mathrm{t}(30)=0.103$, $\mathrm{p}=0.919$, and peppermint before $(\mathrm{M}=6.90, \mathrm{SD}=2.441)$ and after $(\mathrm{M}=6.55, \mathrm{SD}=2.234) ; \mathrm{t}(30)=1.283, \mathrm{p}=0.209$. $\mathrm{P}<0.05$ for cinnamon and $\mathrm{P}>0.05$ for orange, banana, pineapple, and peppermint odorants. Due to the mixed results received we could not conclude any strong opinion on this experiment, however, it would be safer to say that, electrical stimulation of the olfactory mucosa possibly influenced the perceived intensity of cinnamon odorants.

\section{User Perceptions About Future Digital Smell Device}

Further, we conducted a survey to investigated the user perceptions about expected benefits, personal privacy, and 
adoption intention of this device. We defined those factors as follows;

Expected benefits: Previous works have suggested the role of utiltarian factors as an antecedent to technology adoption [49], [50]. In addition to that, we have used hedonic factors as in [51], [50].

Personal privacy: Here, we concerned that possibility of hacking could affect personal privacy. According to [52], [50] concerns of the users on privacy threats prevents the development of trust in the technology.

Adoption intention: Here we tested the expected easiness to use the technology as well as adoption intentions regarding the using and purchasing [53]. Further, works by [54], [55] have shown that adoption intentions can be affected based on the adoption intention of their peers.

\section{1) Research process and data analysis}

The combination of survey and open-ended questions were used in this study. Our sample consisted of 91 participants (35 females, Age range 20 or above). All 91 participants were familiar with using Internet and email. 20 Participants knew about this research before. Out of these 20 participants, 15 participated to the 'Electrical Stimulation of the Nasal Mucosa' experiment that discussed earlier.

Participants received a link to the survey through email. They were supposed to watch a $3 \mathrm{~min}$ and $6 \mathrm{~s}$ long project video before answering the questionnaire. This video provided a quick overview of the research including the concept of electrical stimulation, objectives, procedures for the stimulation, results, and future directions.

The questionnaire we used to collect the data was developed based on the works of [50], [53]. This questionnaire had two sections, first section contained 14 questions with 5-point Likert scales (1 strongly disagree to 5 strongly agree). The second section of the questionnaire contained with 6 openended questions.

We measured the internal consistency reliability of the survey based on Cronbach's alpha. The value of 0.89 obtained showed that the questionnaire is a reliable measure. The 'Cronbach's alpha if items deleted' values for all items were between 0.83 and 0.89 ; which are similar to the Cronbach alpha of the whole scale (0.89), indicating that item deletion will not improve the internal consistency of the questionnaire in any significant way. Therefore, we used all the items in this questionnaire.

\section{2) Findings}

Fig 8 shows the percentage of participants who answered these questions with either 4 (agree) or 5 (strongly agree) on the 5-point Likert scale.

Expected benefits: Related to the expected benefits, $69.2 \%$, $75.8 \%$, and $79.2 \%$ of participants rated that Digital Smell Device could be entertaining, fun, and enjoyable. These findings are in line with open-ended results, for example, participants like this device because it is "fun, easy to use and could open new possibilities". This shows the participant expected hedonic benefits from this device. Further, $56.1 \%$ and $38.5 \%$ of the participants rated this device could increase productivity and efficiency of their life. Some answers received through the qualitative questions were "Because it can ease human life in many situations such as Internet shopping and ordering foods.","It opens a new medium of communication", and "I can communicate olfactory information.", "Sometimes I want to try some new shampoo or body lotion but wonder about the smell. This device if possible it could give the example like going into the store and smell those substances before deciding on brands.", "I can imagine that there is huge potential in such technology for any application involving memory. I could imagine it being very useful in augmented and virtual reality contexts - definitely to increase the experience, impact on immersion, etc.", "Could help in medical industry for patients who are suffering with smell distortion", and "More realistic information can be shared".

Personal privacy: Related to the personal privacy, 59.4\% and $55 \%$ of participants rated that their personal privacy could be in danger if, for example, hackers gain access to the device. Again this finding is in line with our qualitative data like "Someone can misuse and hack the device if it's not protected.", and "As this device is electrically controlled, it will be easy for some people to hack into this device and use it for their own benefits."

Adoption intention: Regarding the adoption intention, $52.8 \%$ and $72.6 \%$ participants expected that future digital smell device will be easy to use. Some comments received through the open ended questions were "Through this device we can see various different experiences in our day to day life and I think it will minimize and easy the work.", "make the life style easy", "It appears that it might be easy to handle and wear". Further, $48.4 \%$ of them want to be one of the first to try but only $28.6 \%$ wanted to use this device in daily life, and $26.4 \%$ of the participants believed that this device can override the natural mechanism of experiencing smells. However, $28.6 \%$ rated that they will be the first one to buy this device. Further $51.7 \%$ said if they have financial resources they would like to buy it. probably, the rest of the participants who rated the device is easy to use or would like try are fallen into the category of 'influenced by peers' as discussed in [54], [55], [53], which means when the people started to use Digital Smell Device the more people will purchase and use in their daily life.

\section{DISCUSSION}

The aim of this research was to electrically stimulate the human olfactory epithelium and to measure and characterize the corresponding sensations. Hence, our stimulations were majorly at the middle concha where olfactory local field potentials are easily acquired [45], while few were at the superior and inferior conchae, based on the results from epithelial biopsies on spread of olfactory mucosa [58] [59]. Stimulations with $1 \mathrm{~mA}$ and $70 \mathrm{~Hz}$ and $1 \mathrm{~mA}$ and $10 \mathrm{~Hz}$ combinations generated smell sensations such as chemical, fragrant, and sweet smells. Furthermore, some participants reported higher intensity levels for certain smells as shown in Fig 7 This indicate evidences that there could be an electrical path to generate smell sensations in human.

Comparison between related works and our research as shown in Table IIII revealed our study till date as the only 


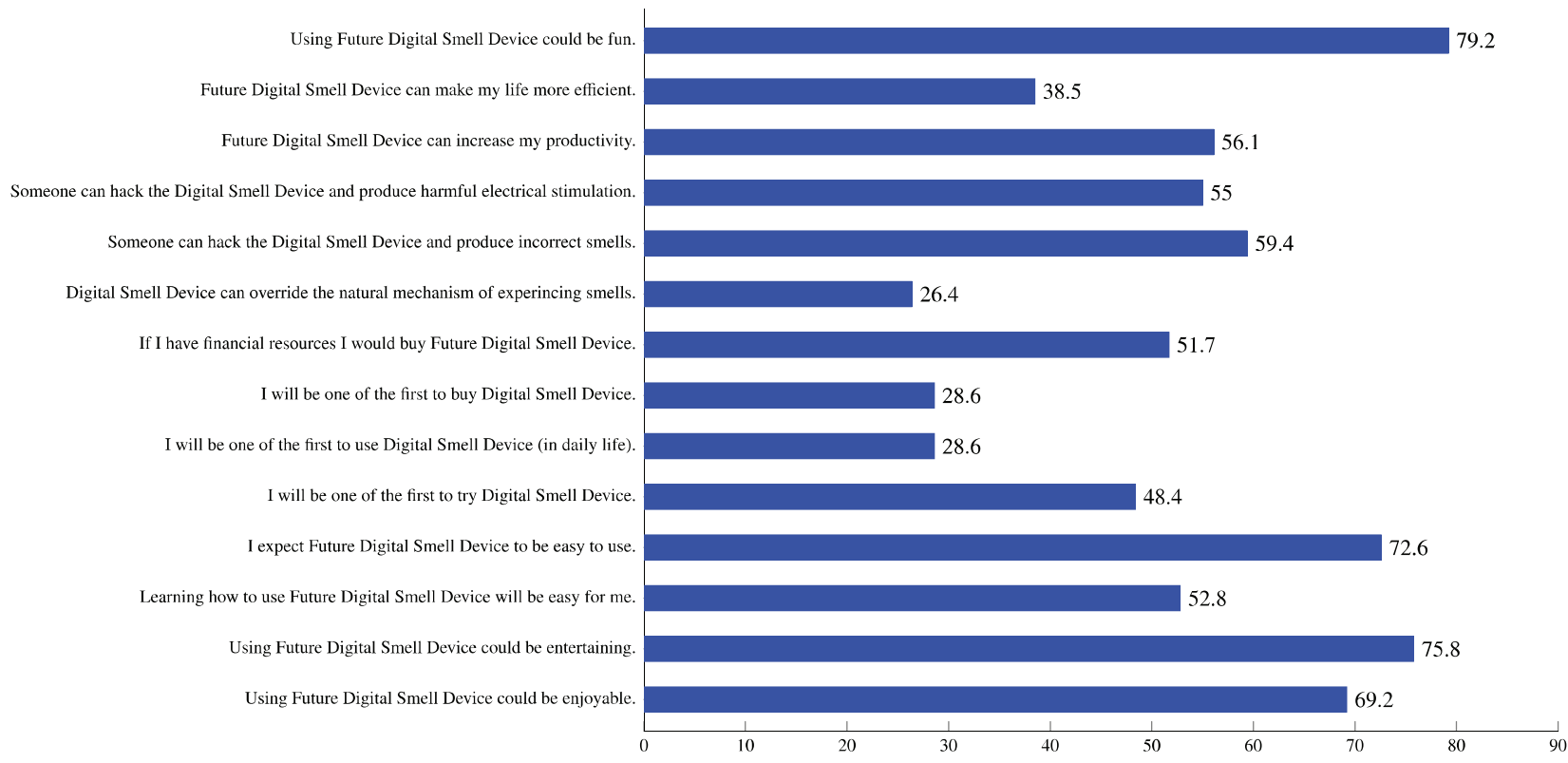

Fig. 8. Percentage of participants who rated either 4 (agree) or 5 (strongly agree) on the 5-point Likert scale.

non-invasive study that was successful on producing smells sensations using electrical stimulation, after the study reported by Uziel [36].

One of the key limitation we have experienced during our experiments was the reluctance of the participants to allow for the insertion of the electrode and camera because of the size of the camera and their concern for hygiene of the electrodes. By using a smaller endoscopic camera probably we may be able improve the usability of the device. Another challange we faced during the experiments was the pain that subjects felt during the electrical stimulation. Anodic stimulation [41] can reduce the pain that subjects feel and therefore, in future we would like to use it as one of the testing method. Another improvement we targeted to do is to provide electrical stimulations on the areas of the nasal cavity where it has minimum or no olfactory receptors (such as lower turbinate) and compare resulting sensations with the sensations produced by electrical stimulation of the areas which are known for the olfactory receptors. Using this method we will be able get a rough estimation on the incorrect user responses for smell sensations.

As the next step of this research, we started to collaborate with some medical experts to do more controlled experiments. This will include a fMRI experiment with stimulating olfactory receptors with natural odorants and electrical stimulation. Participants who already reported virtual smell sensations would participate in to this study. If both stimulation techniques activate approximately same areas of the brain, we will be able to argue that electrical stimulation can reproduce the similar sensation as chemical based smells do. However, this would be the topic for a future full paper.

Also, this method could be used as an alternative for sensory restoration [60] for people who lost their sense of smell due to some medical conditions. However, we acknowledge the challenge in odor discrimination and generalization. To our knowledge, no research has been done to show if neurons have a consistent link to specific odors among individuals. Recent study by [61], has revealed that a specific pattern of neural activity cannot be tied to a class of odors. Furthermore, representation of a given odor will differ among different individuals across the different sections of the brain.

\section{CONCLUSION}

Contributions made by this paper are as follows; first, we described the development of a computer controlled digital device that can stimulate the olfactory receptors using electric pulses. Second, we tested this device on human subjects $(\mathrm{n}=31)$ using parameters which were not previously tested (current : 1-5 mA, frequency : 2-180 Hz ). Third, we presented the results reported for 22 different types of sensations during the electrical stimulation. One fourth of the participants reported some kind of smell sensation, including sweet, chemical, and fragrant. Forth, we tested the odor sniffing ability before and after the electrical stimulation for five odorants and found possibly electrical stimulation influenced the smelling ability for the cinnamon smell. Finally, through a survey, we found that this kind of device would be fun, enjoyable, and useful in future.

Today, Internet communication is mainly based on audio and visual. If electrical stimulation of olfactory receptors can effectively produces smell sensations, it will revolutionize the field of communication. Similar to the users receiving visual/auditory data using a head mounted display (HMD)or using a headphone, and it will be possible to communicate and regenerate smell experiences digitally by small wherable gadgets. Digitizing touch and taste senses [62], [63], [10], [64] have already been achieved experimentally at the research level and could become an everyday standards in the near future. With the digitization of smell, we will be able to 
TABLE III

A COMPARISON BETWEen THE RELATED WORKS AND 'EleCtric SMELl DeVice'

\begin{tabular}{|c|c|c|}
\hline Title & Contributions & Stimulation Parameters \\
\hline $\begin{array}{l}\text { Stimulation of human olfactory neuro- } \\
\text { epithelium by long-term continuous electrical } \\
\text { currents } 36\end{array}$ & $\begin{array}{l}\text { - Anodal stimulation produced odor perceptions, such as vanilla, } \\
\text { almond, and bitter almond } \\
\text { - Cathodal stimulation produced wide ranging burnt odor }\end{array}$ & $\begin{array}{l}\text { Current: } 0.25-0.5 \mathrm{~mA} \text {; and Stimulation dura- } \\
\text { tion: } 10 \mathrm{~s}\end{array}$ \\
\hline $\begin{array}{l}\text { Effects of electrical stimulation of the human } \\
\text { olfactory mucosa } 37\end{array}$ & - Suppressed smell sensations of presented odorants & $\begin{array}{l}\text { - Electrode put inside nasal cavity. Second } \\
\text { electrode located on the right arm with } \\
\text { frequency } 60 \mathrm{~Hz} \text {; and Duration: } 1-10 \mathrm{~s}\end{array}$ \\
\hline $\begin{array}{l}\text { Olfactory bulb potentials to electrical stimu- } \\
\text { lation of the olfactory mucosa } 56\end{array}$ & - Evoked potentials in secondary olfactory neurons. & $\begin{array}{l}- \text { Voltage: } 1-20 \mathrm{~V} \text {; Stimulation Length: } 0.2- \\
0.5 \mathrm{~ms} \text {; The electrodes were placed on the } \\
\text { scalp near forehead }\end{array}$ \\
\hline $\begin{array}{l}\text { Olfactory evoked potential produced by elec- } \\
\text { trical stimulation of the human olfactory mu- } \\
\text { cosa } 57\end{array}$ & - Showed olfactory bulbar potentials & - Current: $2 \mathrm{~mA}$; and Frequency: $0.5 \mathrm{~Hz}$ \\
\hline $\begin{array}{l}\text { From nose to brain: Un-sensed electrical cur- } \\
\text { rents applied in the nose alter activity in deep } \\
\text { brain structures } 41\end{array}$ & $\begin{array}{l}\text { - Some subject reported significant impact on the perceived } \\
\text { intensity of smell when they sniffed during the electrical stimulation }\end{array}$ & $\begin{array}{l}\bullet \text { Current:0.05-0.8 mA; and Frequency:2, 10, } \\
70,90,130,180 \mathrm{~Hz}\end{array}$ \\
\hline $\begin{array}{l}\text { Electrically stimulated olfactory evoked po- } \\
\text { tential in olfactory disturbance [39] }\end{array}$ & - Olfactory evoked potentials were recorded & - Current: $2 \mathrm{~mA}$; and Duration:0.5 ms \\
\hline $\begin{array}{l}\text { Olfactory hallucinations elicited by electrical } \\
\text { stimulation via subdural electrodes: effects } \\
\text { of direct stimulation of olfactory bulb and } \\
\text { tract } 42\end{array}$ & $\begin{array}{l}\text { - Nine subjects perceived unpleasant smells (like bitterness, smoke, } \\
\text { or garbage, while two subject perceived a pleasant smell (like } \\
\text { strawberry or good food) and lastly, five subject did not smell } \\
\text { anything. }\end{array}$ & $\begin{array}{l}\text { - Invasive stimulation of frontal lobe with the } \\
\text { Current: } 3 \mathrm{~mA}, 6 \mathrm{~mA} \text {, and } 9 \mathrm{~mA} \text {; Frequency: } \\
50 \mathrm{~Hz} \text {; and Duration: } 5 \mathrm{~s}\end{array}$ \\
\hline $\begin{array}{l}\text { Olfactory evoked potentials: experimental } \\
\text { and clinical studies [40] }\end{array}$ & - Evoked potentials recorded directly from the olfactory tract & $\begin{array}{l}\text { - Voltage: } 10-50 \mathrm{~V} \text { rectangular pulse; } \\
\text { Duration:0.1-0.2 } \mathrm{ms} \text {; and Frequency:0.1-10 } \\
\mathrm{Hz}\end{array}$ \\
\hline $\begin{array}{l}\text { Electric Smell: Towards Artificially Repro- } \\
\text { ducing Smell Sensations for Future VR and } \\
\text { Multisensory Internet (this paper) }\end{array}$ & $\begin{array}{l}\text { - } 1 \mathrm{~mA} \text { and } 70 \mathrm{~Hz}, 27 \% \text { reported chemical and fragrant smells while } \\
20 \% \text { reported fruity and sweet smells. } \\
\text { - } 1 \mathrm{~mA} \text { and } 10 \mathrm{~Hz}, 27 \% \text { of participants perceived sweet smells } \\
\text { while } 20 \% \text { reported chemical smell sensations. } \\
\text { - Chemical smell was reported } 17 \% \text { or higher for all the different } \\
\text { stimulations } \\
\text { - Significant effects for tingling and pressure sensations obtained. } \\
\text { - Participants reported slightly less perceived intensity of smell for } \\
\text { sniffing after having stimulation }\end{array}$ & $\begin{array}{l}\bullet \text { Current:1-5 mA; Frequency:2, 10, 70, } 180 \\
\text { Hz; Duration: } 10 \mathrm{~s}\end{array}$ \\
\hline
\end{tabular}

experience five basic senses digitally and it will create more applications and opportunities in fields such as human computer interaction, gaming, medicine, and internet shopping.

\section{REFERENCES}

[1] P. Kortum, HCI beyond the GUI: Design for haptic, speech, olfactory, and other nontraditional interfaces. Morgan Kaufmann, 2008.

[2] R. Tortell, D. Luigi, A. Dozois, S. Bouchard, J. F. Morie, and D. Ilan, "The effects of scent and game play experience on memory of a virtual environment," Virtual Reality, vol. 11, no. 1, pp. 61-68, 2007.

[3] J. F. Morie, D.-P. Luigi, C. Lathan, M. Pettersen, and J. M. Vice, "Scent delivery device and method of simulating scent in a virtual environment," Feb. 3 2009, uS Patent 7,484,716.

[4] A. Bodnar, R. Corbett, and D. Nekrasovski, "Aroma: ambient awareness through olfaction in a messaging application," in Proceedings of the 6th international conference on Multimodal interfaces. ACM, 2004, pp. 183-190.

[5] Y. Choi, A. D. Cheok, X. Roman, K. Sugimoto, V. Halupka et al., "Sound perfume: designing a wearable sound and fragrance media for face-to-face interpersonal interaction," in Proceedings of the 8th International Conference on Advances in Computer Entertainment Technology. ACM, 2011, p. 4.

[6] D. McGookin and D. Escobar, "Hajukone: Developing an open source olfactory device," in Proceedings of the 2016 CHI Conference Extended Abstracts on Human Factors in Computing Systems. ACM, 2016, pp. 1721-1728.

[7] S. A. Seah, D. Martinez Plasencia, P. D. Bennett, A. Karnik, V. S Otrocol, J. Knibbe, A. Cockburn, and S. Subramanian, "Sensabubble: a chrono-sensory mid-air display of sight and smell," in Proceedings of the 32nd annual ACM conference on Human factors in computing systems. ACM, 2014, pp. 2863-2872.

[8] "Scent air," March 2018, http://www.scentair.com/why-scentair/scents/.

[9] "Scentee," March 2018, https://scentee.com/.
[10] N. Ranasinghe, K. Karunanayaka, A. D. Cheok, O. N. N. Fernando, H. Nii, and P. Gopalakrishnakone, "Digital taste and smell communication," in Proceedings of the 6th international conference on body area networks. ICST (Institute for Computer Sciences, Social-Informatics and Telecommunications Engineering), 2011, pp. 78-84.

[11] N. Ranasinghe, A. D. Cheok, and R. Nakatsu, "Taste/ip: the sensation of taste for digital communication," in Proceedings of the 14th ACM international conference on Multimodal interaction. ACM, 2012, pp. 409-416.

[12] K. Karunanayaka, N. Johari, S. Hariri, H. Camelia, K. S. Bielawski, and A. D. Cheok, "New thermal taste actuation technology for future multisensory virtual reality and internet," IEEE Transactions on Visualization and Computer Graphics, 2018.

[13] S. Hariri, N. A. Mustafa, K. Karunanayaka, and A. D. Cheok, "Electrical stimulation of olfactory receptors for digitizing smell," in Proceedings of the 2016 workshop on Multimodal Virtual and Augmented Reality. ACM, 2016, p. 4.

[14] K. Karunanayaka, S. K. Ufere, H. Camelia, and C. A. David, "Electric stimulation of human nasal conchae towards reproduction of olfactory sensations." Clinical Medical Image Library, vol. 4, no. 25, pp. 118-119, 2018.

[15] A. D. Cheok and K. Karunanayaka, "Digital smell interface," in Virtual Taste and Smell Technologies for Multisensory Internet and Virtual Reality. Springer, 2018, pp. 93-117.

[16] J. M. Young, C. Friedman, E. M. Williams, J. A. Ross, L. TonnesPriddy, and B. J. Trask, "Different evolutionary processes shaped the mouse and human olfactory receptor gene families," Human molecular genetics, vol. 11, no. 5, pp. 535-546, 2002.

[17] G. M. Shepherd, "The human sense of smell: are we better than we think?" PLoS Biol, vol. 2, no. 5, p. e146, 2004.

[18] J. P. McGann, "Poor human olfaction is a 19th-century myth," Science, vol. 356, no. 6338, p. eaam7263, 2017.

[19] C. Bushdid, M. O. Magnasco, L. B. Vosshall, and A. Keller, "Humans can discriminate more than 1 trillion olfactory stimuli," Science, vol. 343, no. 6177, pp. 1370-1372, 2014.

[20] M. Meister, "Can humans really discriminate 1 trillion odors?" arXiv preprint arXiv:1411.0165, 2014. 
[21] J. M. Annett, "Olfactory memory: A case study in cognitive psychology," The journal of Psychology, vol. 130, no. 3, pp. 309-319, 1996.

[22] V. Danthiir, R. D. Roberts, G. Pallier, and L. Stankov, "What the nose knows: Olfaction and cognitive abilities," Intelligence, vol. 29, no. 4, pp. 337-361, 2001.

[23] C. Youngblut, R. E. Johnston, S. H. Nash, R. A. Wienclaw, and C. A. Will, "Review of virtual environment interface technology." Institute for Defence Analyses Alexandria, Tech. Rep., 1996.

[24] J. C. Leffingwell et al., "Olfaction-update no. 5," Leffingwell reports, vol. 2, no. 1, pp. 1-34, 2002.

[25] L. Buck and R. Axel, "A novel multigene family may encode odorant receptors: a molecular basis for odor recognition," Cell, vol. 65 , no. 1 , pp. 175-187, 1991.

[26] T. Narumi, S. Nishizaka, T. Kajinami, T. Tanikawa, and M. Hirose, "Augmented reality flavors: gustatory display based on edible marker and cross-modal interaction," in Proceedings of the SIGCHI conference on human factors in computing systems. ACM, 2011, pp. 93-102.

[27] T. Yamada, S. Yokoyama, T. Tanikawa, K. Hirota, and M. Hirose, "Wearable olfactory display: Using odor in outdoor environment," in Virtual Reality Conference, 2006. IEEE, 2006, pp. 199-206.

[28] K. Karunanayaka, H. Saadiah, H. Shahroom, and A. D. Cheok, "Methods to develop a low cost laboratory olfactometer for multisensory, psychology, and neuroscience experiments," in Industrial Electronics Society, IECON 2017-43rd Annual Conference of the IEEE. IEEE, 2017, pp. 2882-2887.

[29] M. Obrist, C. Velasco, C. T. Vi, N. Ranasinghe, A. Israr, A. D. Cheok, C. Spence, and P. Gopalakrishnakone, "Touch, taste, \& smell user interfaces: The future of multisensory hci," in Proceedings of the 2016 CHI Conference Extended Abstracts on Human Factors in Computing Systems. ACM, 2016, pp. 3285-3292.

[30] C. T. Vi, D. Ablart, D. Arthur, and M. Obrist, "Gustatory interface: the challenges of 'how' to stimulate the sense of taste," in Proceedings of 2nd ACM SIGCHI International Workshop on Multisensory Approaches to Human-Food Interaction (MHFI'17). ACM, 2017, pp. 29-33.

[31] W. Hürst, D. Iwai, and P. Balakrishnan, "International workshop on multimodal virtual and augmented reality (workshop summary)," in Proceedings of the 18th ACM International Conference on Multimodal Interaction. ACM, 2016, pp. 596-597.

[32] A. Nijholt, C. Velasco, K. Karunanayaka, and G. Huisman, "1st international workshop on multi-sensorial approaches to human-food interaction (workshop summary)," in Proceedings of the 18th ACM International Conference on Multimodal Interaction. ACM, 2016, pp. 601-603.

[33] M. Murer, I. Aslan, and M. Tscheligi, "Loll io: exploring taste as playful modality," in Proceedings of the 7th International Conference on Tangible, Embedded and Embodied Interaction. ACM, 2013, pp. 299-302.

[34] R. Vogel, "Understanding anodal and cathodal stimulation," Dec 2016. [Online]. Available: http://neurologiclabs.com/ understanding-anodal-and-cathodal-stimulation/

[35] E. K. Ellegård, D. Goldsmith, K. D. Hay, and R. P. Morton, "Studies on the relationship between electrogustometry and sour taste perception," Auris Nasus Larynx, vol. 34, no. 4, pp. 477-480, 2007.

[36] A. Uziel, "Stimulation of human olfactory neuro-epithelium by longterm continuous electrical currents," Journal de physiologie, vol. 66, no. 4, pp. 409-422, 1973.

[37] M. Straschill, H. Stahl, and K. Gorkisch, "Effects of electrical stimulation of the human olfactory mucosa," Stereotactic and Functional Neurosurgery, vol. 46, no. 5-6, pp. 286-289, 1984.

[38] T. Ishimaru, T. Shimada, M. Sakumoto, T. Miwa, Y. Kimura, and M. Furukawa, "Olfactory evoked potential produced by electrical stimulation of the human olfactory mucosa," Chemical senses, vol. 22, no. 1, pp. 77-81, 1997.

[39] T. Ishimaru, T. Miwa, T. Shimada, and M. Furukawa, "Electrically stimulated olfactory evoked potential in olfactory disturbance," Annals of Otology, Rhinology \& Laryngology, vol. 111, no. 6, pp. 518-522, 2002.

[40] M. Sato, N. Kodama, T. Sasaki, and M. Ohta, "Olfactory evoked potentials: experimental and clinical studies," Journal of neurosurgery, vol. 85, no. 6, pp. 1122-1126, 1996.

[41] T. Weiss, S. Shushan, A. Ravia, A. Hahamy, L. Secundo, A. Weissbrod, A. Ben-Yakov, Y. Holtzman, S. Cohen-Atsmoni, Y. Roth et al., "From nose to brain: Un-sensed electrical currents applied in the nose alter activity in deep brain structures," Cerebral Cortex, 2016.

[42] G. Kumar, C. Juhász, S. Sood, and E. Asano, "Olfactory hallucinations elicited by electrical stimulation via subdural electrodes: effects of direct stimulation of olfactory bulb and tract," Epilepsy \& Behavior, vol. 24, no. 2, pp. 264-268, 2012

[43] P. G. Barash, Clinical anesthesia. Lippincott Williams \& Wilkins, 2009.

[44] K. A. Seiberling and D. B. Conley, "Aging and olfactory and taste function," Otolaryngologic Clinics of North America, vol. 37, no. 6, pp. 1209-1228, 2004.

[45] H. Lapid and T. Hummel, "Recording odor-evoked response potentials at the human olfactory epithelium," Chemical senses, p. bjs073, 2012.

[46] D. Rojas-Líbano and L. M. Kay, "Interplay between sniffing and odorant sorptive properties in the rat," Journal of Neuroscience, vol. 32, no. 44, pp. $15577-15589,2012$

[47] J. Mainland and N. Sobel, "The sniff is part of the olfactory percept," Chemical senses, vol. 31, no. 2, pp. 181-196, 2006.

[48] J. B. Castro, A. Ramanathan, and C. S. Chennubhotla, "Categorical dimensions of human odor descriptor space revealed by non-negative matrix factorization," PloS one, vol. 8, no. 9, p. e73289, 2013.

[49] W. R. King and J. He, "A meta-analysis of the technology acceptance model," Information \& management, vol. 43, no. 6, pp. 740-755, 2006.

[50] P. A. Rauschnabel, J. He, and Y. K. Ro, "Antecedents to the adoption of augmented reality smart glasses: A closer look at privacy risks," Journal of Business Research, vol. 92, pp. 374-384, 2018.

[51] V. Venkatesh, J. Y. Thong, and X. Xu, "Consumer acceptance and use of information technology: extending the unified theory of acceptance and use of technology," MIS quarterly, pp. 157-178, 2012.

[52] R. Connolly and F. Bannister, "Consumer trust in internet shopping in ireland: towards the development of a more effective trust measurement instrument," Journal of Information Technology, vol. 22, no. 2, pp. 102118, 2007.

[53] P. A. Rauschnabel and Y. K. Ro, "Augmented reality smart glasses: An investigation of technology acceptance drivers," International Journal of Technology Marketing, vol. 11, no. 2, pp. 123-148, 2016.

[54] E. M. Rogers, Diffusion of innovations. Simon and Schuster, 2010.

[55] C. Pescher and M. Spann, "Relevance of actors in bridging positions for product-related information diffusion," Journal of Business Research, vol. 67, no. 8, pp. 1630-1637, 2014.

[56] C. Yamamoto, "Olfactory bulb potentials to electrical stimulation of the olfactory mucosa," The Japanese journal of physiology, vol. 11, no. 5, pp. 545-554, 1961

[57] T. Ishimaru, M. Sakumoto, Y. Kimura, and M. Furukawa, "Olfactory evoked potentials produced by electrical stimulation of the olfactory mucosa," Auris Nasus Larynx, vol. 23, no. 1, pp. 98-104, 1996.

[58] N. E. Rawson and M. H. Ozdener, "Primary culture of the human olfactory neuroepithelium," Epithelial Cell Culture Protocols: Second Edition, pp. 81-93, 2013.

[59] F. Féron, C. Perry, J. J. McGrath, and A. Mackay-Sim, "New techniques for biopsy and culture of human olfactory epithelial neurons," Archives of otolaryngology-head \& neck surgery, vol. 124, no. 8, pp. 861-866, 1998.

[60] F. Fleiner, L. Lau, and . Gktas, "Active olfactory training for the treatment of smelling disorders," Ear, nose, \& throat journal, vol. 91, no. 5, pp. 198-203, 215, May 2012. [Online]. Available: http://europepmc.org/abstract/MED/22614554

[61] E. S. Schaffer, D. D. Stettler, D. Kato, G. B. Choi, R. Axel, and L. Abbott, "Odor perception on the two sides of the brain: Consistency despite randomness," Neuron, vol. 98, no. 4, pp. 736-742, 2018.

[62] G. C. Burdea, Force and Touch Feedback for Virtual Reality. New York, NY, USA: John Wiley \& Sons, Inc., 1996.

[63] J. K. S. Teh, A. D. Cheok, R. L. Peiris, Y. Choi, V. Thuong, and S. Lai, "Huggy pajama: a mobile parent and child hugging communication system," in Proceedings of the 7th international conference on Interaction design and children. ACM, 2008, pp. 250-257.

[64] Y. Aruga and T. Koike, "Taste change of soup by the recreating of sourness and saltiness using the electrical stimulation," in Proceedings of the 6th Augmented Human International Conference. ACM, 2015, pp. 191-192. 


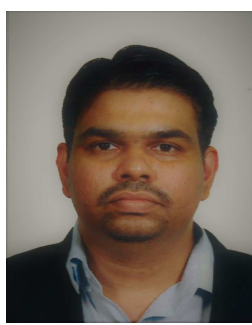

Kasun Karunanayaka is a Senior Lecture in University of Colombo School of Computing, Sri Lanka. He was a former Senior Research Fellow at Imagineering Institute, Iskandar, Malaysia. Kasun has received his $\mathrm{PhD}$ in Electrical and Computer Engineering from National University of Singapore in 2014 and his Bsc (Hons) in Information Technology from University of Moratuwa in 2008. He conduct research related to multisensory communication technologies, magnetic user interfaces, and physical computing. He has co-authored more than 50 sceintific publications for several international journals and conferences. In addition to that he has received several awards for his publications including ACM SIGCHI honorary mentioned award (2015), and IEEE VR Honorable mentioned for the best paper (2018).

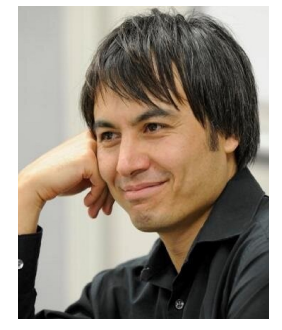

Adrian David Cheok Adrian David Cheok is a Professor of i-University, Tokyo and the Director of the Imagineering Institute, Iskandar Malaysia. He is the Founder and Director of the Mixed Reality Lab, Singapore. He was formerly a Chair Professor at City, University of London, a Full Professor at Keio University, Graduate School of Media Design, associate Professor in the National University of Singapore, and Engineer in Mitsubishi Electric Research Labs, Japan. He has been working on research covering mixed reality, human-computer interfaces, wearable computers and ubiquitous computing, fuzzy systems, embedded systems, and power electronics. 